\title{
A POLÍTICA DE EDUCAÇÃO ESPECIAL NO PARANÁ: MARCOS HISTÓRICOS DA SUA CONSTITUIÇÃO
}

\author{
Neide da Silveira Duarte de Matos ${ }^{1}$ \\ Sonia Mari Shima Barroco ${ }^{2}$
}

\begin{abstract}
Resumo
Pretende-se historicizar os debates políticos que se travaram no Estado do Paraná a partir da Lei de Diretrizes e Bases da Educação Nacional - LDBEN no 4024/1961, quando se manifesta um crescente interesse pelas questões educacionais referentes à pessoa com deficiência. Recuperar a historicidade da Educação Especial como política pública estadual, significa, antes de tudo, que isto nos permite não somente a identificação dos fatos ocorridos, mas lança luz sobre o próprio presente. A apropriação do passado e o seu registro ganham sentido por se referir a um conjunto de ideias e propostas para responder determinados problemas ou questões próprios a um dado momento histórico. Para isso, buscou-se a recuperação documentos referentes ao Brasil e ao Estado do Paraná e de experiências de profissional que atuou na política educacional paranaense, por meio de entrevista e análise documental, trazendo elementos que contribuem para compreensão da educação de pessoas com desenvolvimento atípico em tempos e espaços datados historicamente.
\end{abstract}

Palavras-chave: Educação especial. Política pública. História.

\section{THE POLICY OF SPECIAL EDUCATION IN PARANÁ: HISTORICAL FACTS OF ITS CONSTITUTION}

\begin{abstract}
It is intended to historicize the political debates that took place in the State of Paraná from the Law of Directives and Bases of National Education - LDBEN no 4024/1961, when there is a growing interest in the educational issues related to the person with disability. Recovering the historicity of Special Education as a state public policy means, above all, that this allows us not only to identify the facts that have occurred, but to shed light on the present. The appropriation of the past and its registration make sense because it refers to a set of ideas and proposals to answer certain problems or questions specific to a given historical moment. In order to do this, we sought to retrieve documents referring to Brazil and the State of Paraná and experiences of professionals who worked in the educational policy of Paraná, through interview and documentary analysis, bringing elements that contribute to understanding the education of people with atypical development in times and spaces historically dated.
\end{abstract}

Keywords: Special education. Public policy. History. 


\section{INTRODUÇÃO}

Ao buscar por elementos explicativos para a constituição e o desenvolvimento do psiquismo a Teoria Histórico Cultural (THC) converge com a Pedagogia Histórico-Crítica (PHC), que considera o papel fundamental da educação escolar para tanto. Nesse sentido, ao se tomá-las como norteadoras para o trabalho educativo junto às pessoas com deficiência e/ou com necessidades especiais, entende-se a relevância de se recuperar concepções/ideias e fatos da história dessa modalidade educacional. Reconhece-se que a cada momento ou período histórico as demandas para a garantia e reprodução da vida revelam especificidades que lhes são próprias. A contemporaneidade é reconhecida como o período em que o capitalismo se consolida e assume diferentes modos de se perpetuar. Desde o século XVI o Brasil já estava envolto nos princípios desse sistema, visto que a sua descoberta respondia à lógica de expansão de domínio de certos países e de acumulação de riquezas pelos mesmos. Se desde as grandes navegações do século XVI já se tem a emergência do capitalismo, nos séculos seguintes ele vai se configurando como esse sistema de produção e de organização da vida societária até chegar ao seu estágio atual. Neste, além de contar com a aplicação de alta tecnologia na produção, na grande indústria, pode ser reconhecido por sua reprodução por meio da destruição da natureza e do já criado pelo próprio homem, por meio de guerras, por exemplo, (SAVIANI, 2015). Também pode ser reconhecido por estar em uma fase em que se nota a sua reprodutibilidade incontrolável. (MÉSZARÓS, 2002).

Tudo isso em muito importa a aquele que busca compreender a educação especial, bem como a inclusão escolar, visto que a educação não se põe a parte do modo como a vida e garantida e reproduzida pelos homens. Assim, recuperar aspectos da história da educação e da educação especial se apresenta como uma iniciativa para mais bem compreender os próprios homens que a protagonizam ou que dela são beneficiários diretos. Mesmo que se delimite a abordagem, como no presente caso, a um dado espaço temporal e geográfico, ainda assim, considera-se que os elementos organizados e analisados podem lançar luz para explicar como os homens são ou estão, e como se constituem como tais. Essa afirmação apoia-se na concepção de que o trabalho investigativo, ao pretender capturar e explicar os homens reais de dados períodos históricos e de dados lugares, precisa coloca-los em relação com a vida humana em geral, reconhecendo-se a relação dialética que o singular guarda com o universal.

É relevante que se marque que 'a época da descoberta e do início da colonização do Brasil, as relações vigentes já anunciavam as bases do mercantilismo e do capitalismo. Este país, como tantos outros, foi tomado como colônia, que deveria produzir riqueza para enviar a coroa - Portugal. Assim como os demais países europeus, expunha as demandas que o país deveria suprir, bem como o modo e o ritmo em que isso deveria ser feito. Não sem razão que as ideias veiculadas em todo o processo educacional brasileiro estão imbricadas com as ideias da "coroa dominante"!

Com isso, aponta-se quanto à configuração da educação, seja escolar ou não escolar, em os seus métodos e conteúdos, não se encontra distanciada do mundo da produção, das relações sociais de produção. Assim, entende-se imprescindível que se recupere a história da educação de pessoas com deficiências considerando as demandas do desenvolvimento da sociedade em geral. 
Por esse modo, atentar para a história da Educação Especial, que expressa a história das ideias educacionais e do reconhecimento da educabilidade da pessoa com deficiência, requer que não se busque somente pelos fatos específicos da área, mas que se atente ao desvendamento de uma dada forma de vida instituída.

Destaca-se que a educação é aqui entendida como um processo, antes de mais nada, de humanização. Para A. N. Leontiev (1978, p. 272),

\begin{abstract}
As aquisições do desenvolvimento histórico das aptidões humanas não são simplesmente dadas aos homens nos fenômenos objetivos da cultura material e espiritual que os encarnam, mas são aí apenas postas. Para se apropriar destes resultados, para fazer deles as suas aptidões, "os órgãos da sua individualidade", a criança, o ser humano, deve entrar em relação com os fenômenos do mundo circundante através de outros homens, isto é, num processo de comunicação entre eles. Assim, a criança aprende a atividade adequada. Pela sua função, este processo é, portanto, um processo de educação.
\end{abstract}

Este autor, um dos fundadores da Psicologia Histórico-cultural, expõe que a educação constitui-se em um processo que permite aos homens o desenvolvimento das suas aptidões humanas. Isso se dá ao se apropriarem dos resultados do desenvolvimento processado historicamente, por meio das interações sociais que estabelecem entre si. A educação pode revelar-se de formas muito diversas, conforme as diferentes épocas e locais. Ela abrange desde a mais simples imitação dos atos de pessoas do meio circundante, até complicar-se e especializar-se, ou mesmo dar-se de forma autodidata. (LEONTIEV, 1978). Pode se realizar por meio do ensino e da educação escolar, assumindo diferentes níveis, da educação infantil à superior e pós-graduação.

Leontiev (1978) expõe que a história só se torna possível graças à transmissão das aquisições da cultura humana às novas gerações pela educação. Isso leva à pensar que quanto mais a humanidade desenvolve novos processos de intervir sobre a natureza e de estabelecer relações entre os homens, mais rica se torna a prática sócio-histórica. Isso requisita que a educação se eleve, já que a sua tarefa torna-se mais complexa. Tem-se, pois, que, a cada nova etapa no desenvolvimento da humanidade, há uma nova etapa no desenvolvimento da educação. Isso leva ao reconhecimento de que entre progresso histórico e o progresso da educação há uma imbricada relação, "[...] de modo a se poder julgar o nível geral do desenvolvimento histórico da sociedade pelo nível de desenvolvimento do seu sistema educativo inversamente". (LEONTIEV, 1978, p. 274).

Fica notório que o tempo empregado pela sociedade com a educação das gerações vem se elevando por essas razões citadas, bem como pelo ingresso cada vez mais tardio das pessoas no mercado de trabalho. Não sem razão que a educação escolar vai assumindo formas especializadas. As demandas do mundo do trabalho passam a exigir que a atuação do educador vá se diferenciando, que os sistemas de ensino e os programas de estudos se alterem, que novos métodos pedagógicos sejam aperfeiçoados. Numa sociedade em que cresce a luta para que a educação formal seja para todos; para que haja a universalização do ensino básico e que o acesso ao ensino superior possa estar ao alcance de todos, também aumentam a sofisticação para criar situações impeditivas ou inibitórias para tanto, sobretudo na esfera da educação pública.

Barroco (2007, p 118) aponta: 
[...] ao se tomar o modo como está organizado o sistema educativo formal nas épocas mais recentes, pode-se concluir quanto o saber está especializado, e quanto ele corresponde à própria sociedade capitalista, que se estrutura em uma produção material dividida em infinitas tarefas, dificultando aos indivíduos uma compreensão do todo que envolve o processo produtivo. Esta mesma dificuldade é reproduzida pela educação escolar que, com frequência, leva os indivíduos a terem uma visão parcial da realidade por não compreenderem a dinâmica da vida atual, as relações dos fenômenos entre si, a sua causalidade, bem como as suas implicações para a própria constituição de suas subjetividades.

Sob essas considerações expostas, neste texto tem-se o propósito de recuperar aspectos da historicidade da Educação Especial como política pública no estado do Paraná, delimitando-se o recuo aos anos de 1960, quando se dá a formalização dessa modalidade de ensino no estado.

\section{A EMERGÊNCIA DA EDUCAÇÃO ESPECIAL}

Nas décadas de 1950/60 ocorria um vigoroso debate em torno das propostas para educação brasileira. Nesse período o Brasil adotou medidas que provocaram uma ampla reestruturação político-econômica e cultural, consolidadas na dinâmica de desenvolvimentismo, com vistas a tirar o país do atraso. Tais medidas que passam a ser caracterizadas como reformas, se apresentam como pré-requisito, e ao mesmo tempo impactam a produção, reprodução e qualificação de mão-de-obra, capazes de incorporar novos recursos e técnicas produtivas. Em tal período, o Estado enquanto governo direciona as potencialidades do país no afluxo de capitais estrangeiros, sendo que diferentes setores produtivos e institucionais, tanto da esfera privada quanto da pública, são vistos como necessários à implementação industrial da produção de equipamentos, bens de consumo duráveis, etc. Essas transformações estruturais e conjunturais no Brasil, resultantes dos eventos sócios históricos ocorridos mundialmente, redimensionam as relações de mercado, a vida social, a organização econômica e política. Sobretudo, por políticas públicas impactadas pelas determinações que a reforma do Estado imprime na relação entre sociedade civil e mercado. Para Netto (2006) reformar o Estado se colocou de maneira inadiável. Assim, a educação como uma política pública social de responsabilidade do Estado, assume formas específicas de um projeto político e de uma teoria social para a sociedade como um todo.

Reconhecendo esse contexto, buscou-se por documentos que permitissem caracterizar as diretrizes e normas da Educação Especial e os que orientaram a formação de professores. O levantamento documental realizado nas bases do arquivo digital da Secretaria de Estado da Educação, no Espaço Memória / SEED, arquivo virtual do Conselho Estadual de Educação, acervo da biblioteca da Universidade Estadual do Oeste do Paraná-Unioeste no período de 2015-2017, permitiu constituir uma panorâmica dos elementos que definiram a política dessa modalidade de ensino no estado do Paraná.

Salienta-se que o Paraná seguiu a política pública educacional brasileira que se estabeleceu com a promulgação da Lei de Diretrizes e Bases da Educação Nacional LDBEN n ${ }^{\circ}$ 4.024/61. Coube à educação, por meio de medidas predominantemente econômicas, criar as condições de desenvolvimento exigidas pelo Estado no processo de 


\section{Revista HIIST'TEIDBR On-line}

Artigo

doi: $10.20396 /$ rho.v17i4.8651228

industrialização e urbanização, sobretudo com incrementos nos índices de escolarização. Destaca-se que até 1920 registrava-se um percentual de 65\% da população brasileira na condição de analfabetismo e em 1960 um índice de $40 \%$ da população com mais de 15 anos. (SAVIANI, 2008a). O processo de urbanização e o crescimento da indústria produziram demandas de Políticas Educacionais com a finalidade de capacitar e ampliar a força de trabalho necessária ao desenvolvimento industrial.

Em termos nacionais, na área da Educação Especial o levantamento estatístico publicado pelo Ministério da Educação-MEC data de 1974, um documento que apresenta um montante referente a 96.796 alunos com deficiência atendidos no país - fração representativa a $16,86 \%$ do total de alunos com deficiência em idade escolar que era de aproximadamente 575.000 alunos. (BUENO, 2004). O atendimento especializado que naquele momento se prestava às pessoas com deficiências contava com a atuação das instituições especializadas particulares, Jannuzzi $(1985$, p. 20) esclarece que:

[...] mesmo depois da criação do CENESP [Centro Nacional de Educação Especial] e da reafirmação da Emenda Constitucional n. 12, de 78, que garantia legalmente a instrução especial e gratuita [...] aos portadores de deficiência, continuaram as instituições particulares a atender a esses alunos em maior número que o serviço público. De 1970 a 1974 foram criadas 69 instituições especializadas públicas, enquanto surgiram 213 particulares, isto para a deficiência mental, sendo que, para os deficientes da visão, audição e múltiplos, surgiram 15 públicas e 49 particulares.

Essa ampliação no atendimento se origina da necessidade de assistir as pessoas com deficiências nas áreas de saúde, educação e de garantir-lhes ocupação. Concomitante à expansão ou demanda de universalização da escola pública, a Educação Especial passa a oferecer atendimento e seu objetivo assemelha-se ao que o ensino comum: ocupar o tempo livre das crianças e liberar a família para o trabalho. A educação escolar passa a ser referenciada como prioridade, bem como a expansão de vagas em toda estrutura educacional. Assim, as políticas educacionais da década de 60 e 70, expressas na LDBEN n ${ }^{\circ} 4.024 / 61$, nas Reformas do Ensino Superior, Lei n ${ }^{\circ} 5040 / 68$, do Ensino Fundamental e Médio, Lei n ${ }^{\circ}$ 5692/71, manifestam o papel estratégico que tem a educação no preparo da mão-de-obra. No momento conhecido como "era do milagre econômico", que caracterizou o crescimento produtivo, "[...] valorizava-se a educação em função do desenvolvimento do país, do aumento da produtividade do indivíduo". (JANNUZZI, 2004, p. 142).

Retoma-se um conjunto de acordos firmados na década de 1960, entre o Ministério da Educação (MEC) e United States Agency for Internacional Development (USAID) para organização do campo educacional. Dos acordos MEC/USAID, estabelecidos pelo governo brasileiro com os Estados Unidos, com vistas a atender critérios e demandas do desenvolvimento econômico orientado pelo capital internacional que tinha seus princípios fundamentados na Teoria do Capital Humano (JANNUZZI, 2004), resulta a organização e a estrutura do atendimento educacional aos ditos "excepcionais".

Desse modo, a Educação Especial como política pública também é resultado das determinações estabelecidas com as reformas do Estado. Tem-se, juntamente com a expansão da educação geral, a instituição e o crescimento da Educação Especial, que cumpre com o objetivo em ocupar o tempo livre das crianças e, assim, liberar a família para o 
trabalho - fator que contribui para o progresso e o desenvolvimento do país. A tendência presente nas iniciativas oficiais se materializa com a criação de oficinas e a implantação de várias propostas de preparação para o trabalho nas instituições especializadas. Somente a partir de 1990, se intensificou a preocupação com a educação escolar de alunos com deficiência, indicando a necessidade de mudanças para que todos pudessem ter acesso, permanência e aprendizado nas escolas de ensino regular (UNESCO, 1994). Kassar (2011) aponta que novos conceitos foram estabelecidos na LDBEN no 9.394/96, ao instituir que a modalidade de Educação Especial deveria ser oferecida preferencialmente na rede regular de ensino, para educandos portadores de necessidades especiais ${ }^{3}$.

\section{EDUCAÇÃO ESPECIAL NO PARANÁ E AS ESTRATÉGIAS DE EXPANSÃO: 1964 A 2016}

Durante quase um século, no Brasil, o atendimento educacional às pessoas com deficiência, foi realizado por intermédio de iniciativas oficiais e/ou particulares isoladas, refletindo o interesse de alguns educadores por este atendimento. (JANNUZZI, 2004; MAZZOTTA, 2001). Tal como se passava em vários países no mundo todo, a maioria das instituições que desenvolviam um trabalho educativo voltado às pessoas com deficiência tinha caráter filantrópico e era realizado por associações e institutos, sendo que, em muitos casos, eram ligadas a segmentos religiosos, os quais conservavam o atendimento educacional no âmbito da caridade ${ }^{4}$.

Considerando os investimentos públicos junto às secretarias de educação e às instituições especializadas em educação de pessoas com deficiências, em 1958 o Ministério de Educação começa a prestar assistência técnica-financeira com campanhas ${ }^{5}$ nacionais para educação de surdos, cegos e pessoas com deficiência intelectual. É, também, no final da década de 1950, que a expansão da Educação Especial, embora lentamente, passou a ocorrer nas escolas regulares. Segundo Mazzotta (2001), nesse período havia no Brasil cerca de 54 instituições de ensino regular mantidos pelo Estado que atendiam pessoas com deficiências em classes especiais e 11 instituições especializadas, subvencionadas pelo poder público para o atendimento as pessoas com deficiência mental, física, visual e auditiva. Nas décadas de 1960 e 1970 tais serviços foram paulatinamente sendo ampliados para todos os estados do Sul, Rio de Janeiro, Minas Gerais, São Paulo Bahia e Pernambuco.

Quanto à instituição de uma política educacional nacional, Mazzotta (2001) aponta a LDBEN n ${ }^{\circ}$ 4.024, promulgada em 20 de dezembro de 1961, como marco inicial das ações oficiais do poder público na área de Educação Especial. A referida legislação contempla o atendimento à pessoa com deficiência, "educação de excepcionais", nos artigos 88 e 89 . No art. 88 fica assegurado o atendimento à pessoa com deficiência que, dentro do possível, deveria ser oferecido na educação regular, "[...] Art. 88 - A educação de excepcionais deve, no que for possível, enquadrar-se no sistema geral de ensino, a fim de integrá-lo na comunidade". Já o artigo 89 indicava a garantia de auxílio financeiro às instituições particulares que recebessem pessoas com deficiência "[...] Art. 89 - Toda iniciativa privada considerada eficiente pelos conselhos estaduais, receberá dos poderes políticos tratamento especial mediante bolsas de estudos, empréstimos e subvenções". (BRASIL, 1961). 


\section{Revista HIISTEYIDIR On-line}

Com a revisão da $\operatorname{LDBEN~n}^{\circ}$ 4.024/61 pela Lei $\mathrm{N}^{\circ}$ 5.692/71, tem-se no aparato legal a definição do público alvo da Educação Especial e esta passa a ser uma das prioridades do I Plano Setorial de Educação e Cultura (1972-1974) e no Projeto Prioritário no 35. Foi neste contexto que, em junho de 1973, se constitui no Ministério de Educação o primeiro órgão educacional responsável pela definição da política de Educação Especial, o Centro Nacional de Educação Especial (CENESP), criado pelo Decreto 72.425, de 3 de julho de 1973.

[...] em nível governamental uma ação política mais efetiva, que poderia organizar
o que se vinha realizando precariamente na sociedade: escolas, instituições para
ensino especializado desse alunado, formação para o trabalho, às vezes mais, às
vezes menos integrados à educação regular, dependendo, em parte, da percepção
da família, dos diversos elementos sensibilizados ao tema, militantes dessa
educação e da própria comunidade. Fatores conjunturais externos e internos
podem servir como hipóteses explicativas para a criação do CENESP.
(JANNUZZI, 2004, p. 137).

É observado que no mesmo período as secretarias estaduais de educação, que é o caso do estado do Paraná, começam a implantar setores da Educação Especial para administrar recursos financeiros repassados pelo CENESP e dar início a Política de formação de professores. (BUENO, 2002). A Educação Especial, por meio do Projeto Prioritário n. ${ }^{\circ}$ 35, passa a ser política preferencial no país. Jannuzzi (1985, p. 63, grifo da autora) esclarece que o investimento em Política Pública para pessoas com deficiências baseava-se no argumento de que para "[...] cada dólar dispensado em educação especial, havia a possibilidade de um lucro de 40 dólares, pois que liberava para o trabalho não só o 'excepcional', o PNE, mas a família que cuidava dele". No final da década de setenta são implantados os primeiros cursos de formação de professores para atuar na área de educação especial. (BUENO, 2002).

No Paraná, as políticas voltadas para o atendimento educacional das pessoas com deficiência, ou seja, a política de Educação Especial, se configura a partir de 1963, quando por meio do Decreto ${ }^{\circ} 10.527$ de janeiro de 1963, a Secretaria de Estado da Educação SEED - criou os Serviços de Educação de Excepcionais. Após oito anos de implantação, os Serviços de Educação de Excepcionais foram reestruturados por meio do Decreto $\mathrm{n}^{\circ}$. 1.083 de 19 de novembro de 1971, e o órgão responsável pela Educação Especial na Secretaria de Estado passa a ser Departamento de Educação Especial - DEE/SEED.

Conforme dados pesquisados sobre a Educação Especial no Estado do Paraná, esta se constitui em estreita relação com os fatos históricos que marcaram a modalidade de ensino no contexto nacional, ou seja, sobre forte influência das tendências pedagógicas e organismos internacionais. Os documentos revelam que a consolidação da Educação Especial para as pessoas com deficiências no Paraná ocorreu "[...] nas escolas especiais e nos programas especializados na rede pública estadual”. (PARANÁ, 2006).

Segundo Canziani (1985, p. 61), o atendimento as pessoas com deficiência, até a década de 1960, se constituía de forma esparsa e unicamente pela iniciativa privada. O Instituto Paranaense de Cegos em Curitiba - IPC destaca-se como a primeira instituição de assistência e educação para as pessoas com deficiência, fundada em 1939. Na década de 1950 outras instituições de Educação Especial foram criadas por entidades e também lideranças comunitárias, destas, cinco na capital Curitiba e duas na cidade de Londrina. $\mathrm{O}$ 


\section{Revista HIISTEYIDBR On-line}

atendimento no âmbito das instituições públicas de ensino somente acontece em 1958 com a criação no Centro Educacional Guaíra em Curitiba e a direção da professora e psicóloga Pórcia dos Guimarães Alves. Este Centro ofereceu a primeira classe especial em escola da rede pública de ensino do Paraná e também a primeira no Brasil.

Em 1961, foi criada a Escola Mercedes Stresser, que após treze anos de funcionamento foi transformada no Centro de Habilitação Profissional - ante o desafio de se preparar sua clientela para o trabalho. Também em novembro de 1961, conforme Canziani (2017), surge em Curitiba a primeira iniciativa de formação para o atendimento em Educação Especial com o Ciclo de Conferências. Por iniciativa do Secretário Estadual de Saúde e pai de uma criança com diagnóstico de deficiência mental, Dr. Justino Alves Pereira, que manifestou dois objetivos: a melhorar o sistema de saúde no Estado e a implantar um serviço de Educação Especial assistido pelo governo. O evento trouxe uma abordagem multidisciplinar sobre a Prevenção ${ }^{6}$ e Educação Especial com a participação de diversos profissionais como: Antonio Blanco Léfèvre-Neurologista da USP, Aydil Macedo de Queiroz-Psicóloga da PUC de São Paulo, Jay Arruda Toledo Pizza-Orientadora Pedagógica do Serviço de Higiene Escolar de São Paulo, Olívia Pereira Especialista em Pedagogia Terapêutica e Stanislay Krynski-Psiquiatra da PUC e USP de São Paulo. Nota-se que, enquanto havia a demanda de preparar para o trabalho, havia também a necessidade de se trabalhar com a prevenção de deficiências. A ciência, sobretudo no campo da medicina, tinha muito a desvendar!

Dois anos depois a Educação Especial passa a compor o regulamento e a estrutura da Secretaria da Educação e Cultura do Paraná, e o serviço concentra incialmente suas atividades no desenvolvimento de ações com a comunidade para discutir aspectos relacionados à prevenção, o atendimento, a integração social das pessoas com deficiência. Para tanto, realizou-se na capital e no interior do Estado palestras de sensibilização com os Núcleos Regionais de Ensino - NRE - e autoridades, tais como: juízes, religiosos, comandantes do Corpo de Bombeiros, exército, diretores e professores de escolas e a comunidade para implantar o atendimento educacional às pessoas com deficiências. Nesse sentido, grandes eventos foram promovidos e com eles foram implantadas 84 entidades especializadas que contaram com o benefício de recursos oficiais, abrangendo: centros de educação precoce, escolas especiais, centros de reabilitação e centros de profissionalização. (CANZIANI, 2017).

As instituições especializadas se expandiram, gradativamente, para o interior do Estado. Paralelamente, o ensino regular também foi se ampliando formando as classes especiais e salas de recursos, ensino itinerante, programas de profissionalização de adolescentes e jovens com deficiência, formação de professores para educação especial com a oferta de mais de oitenta cursos na capital e no interior do Estado, constituição de equipes multidisciplinares, assessoria e atendimento às Secretarias de Educação de diversos Estados e de outras instituições, inclusive fora do país, para implantação e/ou orientação dos serviços e programas de educação especial. (CANZIANI, 1985).

Mesmo com todo o esforço de profissionais e diferentes instâncias da sociedade, Canziani (2017), assevera que até a década de 1980 o sistema oficial de ensino para educação especial ainda era incipiente. Declara a autora que, muitas das escolas especiais ainda não 
Artigo

doi: $10.20396 /$ rho.v17i4.8651228

tinham estabelecido vínculo com o sistema oficial de ensino e a educação especial se encarregava mais dos cuidados que a formação acadêmica das pessoas com deficiência.

Entre o final da década de 1980 até 1994, o atendimento às pessoas com deficiência estava sendo oferecido em 271 municípios do Paraná. Dados que se referem especificamente a 1.433 instituições especializadas para o atendimento na área intelectual, 289 na área auditiva, 210 na área visual, 23 na área da deficiência física, 15 instituições com múltiplos atendimentos, 7 para alunos com condutas típicas, 5 em distúrbios de aprendizagem e 1 para o atendimento de alunos com múltiplas deficiências. (PARANÁ, 1994).

Após uma década, e sob os referenciais da LDBEN Nº 9.394/96, quando a Educação Especial passa a ser definida como "[...] a modalidade de educação escolar, oferecida preferencialmente na rede regular de ensino, para educandos portadores de necessidades especiais" (BRASIL, 1996, p. 24), observa-se que dos 399 municípios do Estado do Paraná, 367 possuem algum tipo de atendimento educacional especializado (Sala de Recursos, Classes Especiais, Centros de Atendimentos Especializados e Escolas Especiais) o que se traduz um percentual de 92\% dos municípios. Deste, concentram-se 1762 atendimentos oferecidos pela rede municipal, 273 pela rede estadual e 360 escolas especiais conveniadas. (PARANÁ, 2016).

Entretanto, dos 58.730 alunos matriculados nos atendimentos de educação especial, 38.190 são atendidos pela rede conveniada e/ou escolas especiais e 20.540 pela rede municipal ou estadual de ensino. Em 2014, os dados expressam 63.500 matrículas na Educação Especial, considerando Escolas Especiais, Classes Especiais e Atendimento Educacional Especializado ${ }^{7}$. As matrículas representam 35.158 alunos na rede conveniada e/ou escolas especiais e 27.718 compõe o público alvo da educação especial na rede municipal ou estadual de ensino. (PARANÁ, 2016).

Isso demonstra que, mesmo com a oficialização de iniciativas legais que abrangem a Educação Especial, essas não se encontram necessariamente atreladas ao compromisso estatal em provê-las, ou seja, ao mesmo tempo em que se vislumbraram novas possibilidades de articulação da Educação Especial ao sistema geral de ensino, contraditoriamente, os dados revelam a forma de atendimento historicamente instituída, onde o atendimento educacional especializado está em sua maioria sob a responsabilidade da rede conveniada.

Recuperar essa história permite identificar documentos e fatos que concretizam um projeto social que explicita um modis vivendi administrado pelo governo do Estado. Assim, sem intenção de apresentar os dados de forma linear, trouxemos aqui o que representou em termos de diretriz educacional, a Política Pública de Educação Especial no Paraná. Essa recuperação permite que se identifiquem os governos e alguns encaminhamentos para o atendimento educacional às pessoas com deficiência e/ou, o que hoje se denomina, necessidade especiais, transtornos globais do desenvolvimento e altas habilidades.

\section{DOCUMENTOS NORTEADORES DO ESTADO DO PARANÁ}

Desde 1961 até o ano de 2017, o Paraná contou com 20 governadores, de diferentes partidos políticos (PMDB, PDT, PFL, PSDB), sendo que foram formulados e aprovados documentos tais como: 
Quadro 01 - Alguns documentos legais e diretivos da Política de Educação Especial no Paraná

\begin{tabular}{|c|c|}
\hline Documento & Finalidade \\
\hline Portaria $\mathrm{n}^{\circ} 4.252 / 66$ & $\begin{array}{l}\text { autorizar o funcionamento do I Curso de Aperfeiçoamento } \\
\text { para o ensino Especializado }\end{array}$ \\
\hline Deliberação no 008/78 & $\begin{array}{l}\text { estabelecer normas para Educação Especial no Sistema } \\
\text { Estadual de Ensino }\end{array}$ \\
\hline Deliberação $n^{\circ} 004 / 83$ & regulamentar o Artigo $9^{\circ}$ da Lei ${ }^{\circ} 5.692 / 71$ \\
\hline Deliberação 025/84 & $\begin{array}{l}\text { estabelecer normas para cursos de formação de professores } \\
\text { para a Educação Especial, na forma de Estudos Adicionais }\end{array}$ \\
\hline Deliberação $n^{\circ}$ 20/86 & $\begin{array}{l}\text { estabelecer normas para Educação Especial no Sistema de } \\
\text { Ensino }\end{array}$ \\
\hline $\begin{array}{l}\text { Instrução } \quad \text { Normativa } \\
\text { Conjunta no } 02 / 92\end{array}$ & $\begin{array}{l}\text { estabelecer critérios para condução da Educação Especial } \\
\text { no processo de municipalização }\end{array}$ \\
\hline $\begin{array}{l}\text { Fundamentos Teórico- } \\
\text { Metodológicos para a } \\
\text { Educação Especial }\end{array}$ & orientar o trabalho pedagógico e formação de professores \\
\hline $\begin{array}{l}\text { Deliberação } \mathrm{n}^{\circ} \quad 02 / 03 \text { do } \\
\text { Conselho Estadual de } \\
\text { Educação }\end{array}$ & $\begin{array}{l}\text { estabelecer normas para a Educação Especial, modalidade } \\
\text { da Educação Básica para alunos com necessidades } \\
\text { educacionais especiais, no Sistema de Ensino do Estado do } \\
\text { Paraná }\end{array}$ \\
\hline $\begin{array}{l}\text { Diretrizes Curriculares da } \\
\text { Educação Especial para a } \\
\text { construção de currículos } \\
\text { inclusivos - 2006; }\end{array}$ & $\begin{array}{l}\text { orientar o currículo para toda a Rede Pública Estadual de } \\
\text { Ensino }\end{array}$ \\
\hline $\begin{array}{ll}\text { Caderno de Apoio } \\
\text { Pedagógico }-2008\end{array}$ & orientar o trabalho pedagógico e formação de professores \\
\hline Parecer 180/2010 & $\begin{array}{l}\text { dispor sobre a autorização e alteração de denominação das } \\
\text { Escolas Especiais de Educação Especial para Escola de } \\
\text { Educação Básica, na modalidade de Educação Especial }\end{array}$ \\
\hline Lei $\mathrm{n}^{\circ} 18.492 / 14$ & $\begin{array}{l}\text { estabelecer metas para o Plano Estadual de Educação (2014- } \\
\text { 2024) }\end{array}$ \\
\hline $\begin{array}{l}\text { Deliberação nº2/2016- } \\
\text { CEE }\end{array}$ & $\begin{array}{l}\text { instituir normas para a Modalidade Educação Especial no } \\
\text { Sistema Estadual de Ensino }\end{array}$ \\
\hline
\end{tabular}

Fonte: Elaborada pelas autoras, 2017.

Como se pode observar nos aspectos normativos, a trajetória do reconhecimento e da educabilidade da pessoa com deficiência no Paraná ganha expressividade no processo de redemocratização (1980-1990), quando também se constrói o novo marco jurídico com a Constituição Federal de 1988 e a Constituição Estadual em 1989. Identifica-se este período como de transição democrática e/ou instauração da Nova República, momento pelo qual o mundo, mas especialmente a sociedade brasileira passou por grande efervescência política, com intensa participação da sociedade civil na formulação da nova conjuntura do país. Tendo em vista a luta desencadeada para garantia de espaços de participação e a conquista 
de direitos que ampliam as condições da existência humana. A Constituição, em seus princípios, aponta para defesa de uma proposta de sociedade que precisa reduzir as desigualdades e promover a justiça social pela garantia dos direitos humanos que, para tanto, exigem do Estado um investimento na implementação e concretização de seu conteúdo essencial: a dignidade da pessoa humana, conforme os art. $1^{\circ}, 3^{\circ}$. (BRASIL, 1988).

Considerando que a Constituição Federal, pós-ditadura militar (1964-1984) em seus mecanismos normativos busca consolidar e ampliar direitos coletivos e sociais para grupos histórica e culturalmente vulnerabilizados, retrospectivamente, podemos ver esse período como a era da transformação social que tem a força da fraqueza das políticas até então desenvolvidas. Identifica-se uma considerável ampliação das atribuições do Estado as quais tornaram operantes vários marcos regulatórios e subsidiaram os procedimentos de implementação das políticas públicas que se mostraram como fortaleza a vida social e o desenvolvimento humano.

\section{FORMAÇÃO DOS PROFESSORES: LDBEN No 4024/61 A LDBEN 9394/96}

Os direitos expressos na legislação referentes à escolarização da pessoa com deficiência colocam-se como um devir para formação de professores. O professor necessita compreender a diversidade e o momento histórico demandava que a formação de professores fosse alvo de atenção de governantes e da própria sociedade. Com o desenvolvimento da ciência encontramos esforços para explicar a deficiência. Assim, o conhecimento a respeito do desenvolvimento humano e de suas patologias vai se constituindo. Percebe-se que sobre os avanços científicos, há também uma mudança nas práticas relacionadas às pessoas com deficiência. Estas não são mais vistas como incapazes, mas como minorias privadas do acesso aos direitos sociais.

Com a revisão da LDBEN 4024/61 pela lei $n^{\circ}$ 5692/71, o Parecer 842/72 - CFE considera a preparação de especialista se recomenda às universidades desenvolver estudos e pesquisas específicos.

Dessa forma, no final da década de 1970 surgiram os Cursos de Estudos Adicionais para a Educação Especial e foram expandidos ao interior do Estado junto às Universidades. Amparada pela Deliberação 020/86, a formação de professores para a Educação Especial no Paraná aconteceu basicamente por meio de Estudos Adicionais, Especialização Lato Sensu e nos cursos de Pedagogia com habilitação em Educação Especial. A Especialização Lato Sensu teve início em 1984 na área de Deficiência Mental, na então Faculdade de Filosofia Ciências e Letras de Guarapuava - FAFIG, hoje Universidade Estadual do Centro-Oeste UNICENTRO. Já a habilitação em Educação Especial no curso de Pedagogia foi oferecida a partir de 1996 em duas universidades: UNICENTRO (Irati e Guarapuava) e UEPG (Ponta Grossa).

Do período de 1970 a 1980, destaca-se o caderno intitulado "Participação da Comunidade na Integração do Deficiente Mental" (1985), de autoria de Maria de Lourdes B. Canziani como uma orientação ao trabalho pedagógico. A referida professora coordenou a implantação da Política de Educação Especial na Secretaria de Estado da Educação do 


\section{Revista HIISTEYIDBR On-line}

Paraná no período de 1963 a 1983. Na obra, Canziani traz dados importantes que revelam a história da Educação Especial e menciona documentos primários de 1961 a 1983, dentre os quais se destacam: Resoluções, Pareceres, Decretos, Portarias e Deliberações do Conselho Estadual de Educação/PR para garantir a formação de professores e a expansão do atendimento educacional às pessoas com deficiências.

Há cadernos referentes à primeira ação descentralizada no processo de formação de professores que podem ser encontrados nos acervos da Biblioteca da Unioeste - Cascavel. Os materiais contemplam as diferentes áreas da deficiência, a coletânea intitulada: "Projeto Especial Multinacional de Educação Brasil-Paraguai-Uruguai", que foi publicada em 1977 pela Organização dos Estados Americanos - OEA/MEC em pareceria- com a CENESP. Este projeto contempla uma formação de professores que se fez de forma decentralizada.

A partir da LDBEN 9394/1996 a Deliberação 02/03 - CEE/PR, conforme o art. 33, indica a formação de professores para a educação especial, em nível superior. Esta deverá ser ofertada em cursos de licenciatura em educação especial; em curso de pós-graduação específico para a educação especial; em programas especiais de complementação pedagógica.

O documento também determina que todos os estabelecimentos de ensino que atendem alunos com necessidades educacionais especiais deverão ter em sua equipe técnicopedagógica no mínimo um profissional com habilitação ou especialização na modalidade Educação Especial.

Os cursos de formação de professores (licenciaturas) não oportunizavam um domínio mais generalizado sobre o desenvolvimento e a aprendizagem de pessoas sob as condições de deficiência intelectual, deficiências visual, auditiva, física neuromotora e de transtornos globais do desenvolvimento. Isso, somado ao permitido pela LDBEN 9394/96 e a Deliberação 02/03, constituiu-se um fator propulsor para a oferta de cursos de especialização lato sensu, visando atender às demandas de escolarização de pessoas sob tais condições. Conforme se seguiram os anos, os professores da educação básica tinham que se graduar no ensino superior, de modo que a formação e a habilitação em nível de Estudos Adicionais foi cedendo lugar a este modelo citado. É possível dizer que a formação do quadro de professores especialistas constitui-se um plano de negócio, com a criação ou o incremento de instituições formativas (criação de institutos, por exemplo). Para esta análise, destacamos o artigo 59 da LDBEN 9394/96 que apresenta como requisitos para educação especial [...] professores com especialização adequada em nível médio ou superior, para atendimento especializado, bem como professores do ensino regular capacitados para a integração desses educandos nas classes comuns. (BRASIL, 2004, p. 329).

A legislação expressa, no texto e na prática, forte influência das políticas econômicas, e, dessa forma, alteram os indicadores da educação e, em especial, da formação de professores. Bueno (2002, p. 25) considera que, mesmo com, “[...] a determinação de obrigatoriedade de formação desse professor em nível superior, a participação da universidade brasileira como um todo, no que se refere às políticas de educação especial, parece exercer pequeno papel". E, neste sentido nos questionamos: como compreender e atuar na formação das próximas gerações e ao mesmo tempo propor o enfrentamento de contradições que se avolumam se ao professor é negado os conteúdos relevantes que explicam a sociedade, o desenvolvimento humano e a relação ensino-aprendizagem? 


\section{Revista HIISTESIDBR On-lime}

Saviani (2008b, p. 93) explica que

[...] a educação é, sim determinada pela sociedade, mas que essa determinação é relativa e na forma da ação recíproca, o que significa que o determinado reage sobre o determinante. Consequentemente, a educação também interfere sobre a sociedade, podendo contribuir para sua própria transformação.

Desse modo, se a Pedagogia Histórico-Crítica toma como base o desenvolvimento material da sociedade e a determinação das condições de existência humana, entende-se que esta possa se constituir em uma força ao conceber a educação enquanto um ato de produzir, intencionalmente, a humanidade, que é produzida historicamente pela coletividade. E ao mesmo tempo assegurar

[...] o saber que diretamente interessa à educação é aquele que emerge como resultado do processo de aprendizagem, como resultado do trabalho educativo. Entretanto para chegar a esse resultado a educação tem que partir, tem que tomar como referência, como matéria prima de sua atividade, o saber objetivo produzido historicamente. (SAVIANI, 2008b, p. 7).

\section{CONSIDERAÇÕES FINAIS}

A recuperação de documentos do Paraná permitiram vislumbrar a constituição da Educação Especial enquanto política de estado. Nesse sentido, é possível que se reconheça sua congruência e convergência com a história da Educação Especial no Brasil, no sentido de guardar intrínseca relação com as demandas do mundo do trabalho, de expressar os anseios pela observação dos direitos humanos, entre outros pontos. Mas, também se deve considerar quanto às políticas públicas não se fazem à parte da luta de classes.

Tratar de políticas públicas tem sido algo cada vez mais recorrente nos âmbitos da Educação e da Psicologia, enquanto áreas de investigação e campos de atuação profissional. Sua abordagem é de grande abrangência, e se pode aproximar desde a sua definição semântica e programática, bem como suas transformações históricas, chegando-se ao modo como elas são aplicadas e avaliadas, entre outros aspectos. Tem-se acompanhado que, via de regra, a vida em sociedade tem sido administrada pela figura do Estado, desde o advento do Estado Moderno ou burguês, no século XVI e que este não é neutro. Antes, mesmo quando constituído democraticamente pelo povo, tende a expressar de início ou em última instância o seu compromisso com uma dada classe social: a detentora da riqueza.

$\mathrm{Na}$ luta para que a riqueza material e não material possa ser mais bem distribuída, circulada, visto que a apropriação do já criado constitui-se em acervo que permite novas elaborações, criações, objetivações, recuperar a história das ideias e dos fatos educacionais permitem dimensionar e compreender as políticas que passam a dirigir a educação formal.

Desde a década de 1960 está em pauta o atendimento educacional às pessoas com deficiência, porém os conteúdos preservados pelas fontes não significam que estamos diante de um produto consolidado. A legislação investigada como fonte documental representa uma posição do Estado sobre a Educação Especial em determinado período, como expressão possível da correlação de forças entre as classes sociais. O conjunto de leis nos permite compreender o modo como à Educação Especial foi se constituindo e a forma como está 
hoje, considerando seus avanços e retrocessos e as possibilidades de estabelecer outros procedimentos investigativos e práticos.

Desse modo, ao analisar a história da educação especial no Paraná podemos nos dar conta dos vários sujeitos envolvidos no processo educativo e aprofundar o conhecimento sobre a relação ensino-aprendizagem e a formação das pessoas com deficiência. O esforço no desenvolvimento investigativo vincula, evidentemente, categorias como a de organização e vida econômica, política, cultural e educativa, ou seja, compreendemos que ambos os aspectos estão invariavelmente em estreita ligação com a gênese e evolução da política pública de Educação Especial que vem sendo implementada no estado, bem como o sentido do efeito formativo que esta representa sobre o desenvolvimento humano. Assim, compreender o passado pressupõe entender as lutas travadas no processo de desenvolvimento pelo qual passamos, conhecer a sociedade em que estamos vivendo, sua organização, sua forma de funcionamento, suas contradições, princípios e fins da educação que se propõe e as exigências que lhe são impostas.

\section{REFERÊNCIAS}

BARROCO, S. M. S. A educação especial do novo homem soviético e a psicologia de L. S. Vigotski: implicações e contribuições para a psicologia e a educação atuais. 2007. $414 \mathrm{f}$. Tese (Doutorado em Educação Escolar) - Faculdade de Ciências e Letras de Araraquara, Universidade Estadual Paulista, Araraquara, 2007.

BRASIL. Coleção de Leis do Brasil - 1971, v. 5, 1971.

BRASIL. Conselho Nacional de Educação. Parecer 17/2001, de 3 de julho de 2001. Diretrizes Nacionais para a Educação Especial na Educação Básica. In: Direito à Educação: Subsídios para gestão dos sistemas educacionais: orientações gerais e marcos legais. Org. GOTTI, M. O. [et.al]. Brasília: MEC/SEESP, 2004.

BRASIL. Constituição (1988). Presidência da República. Constituição da República Federativa do Brasil de 1988. Brasília: Palácio do Planalto, 1988. Disponível em: <http: //www.planalto.gov.br/ccivil_03/constituicao/constituicao.htm>. Acesso em: 20 jan. 2016.

BRASIL. Lei de Diretrizes e Bases da Educação Nacional. LDBEN nº 4.024/1961. 1961.

BRASIL. Lei n. 9.394, de 20 de dezembro de 1996. Estabelece as diretrizes e bases da educação nacional. Brasília, DF: Palácio do Planalto, 1996. Disponível em: <http://www.planalto.gov.br/ccivil_03/leis/L9394.htm>. Acesso em: 01 out. 2017.

BUENO. J. G. S. A educação especial nas universidades brasileiras. Brasília: Ministério da Educação, Secretaria de Educação Especial, 2002.

BUENO. J. G. S. Educação especial brasileira: integração/segregação do aluno diferente. 2. ed. São Paulo: Editora EDUC, 2004. 
CANZIANI, M. de. L. Educação especial: visão de um processo dinâmico e integrado. Curitiba: Editora Universitária Chaampagnat, 1985.

CANZIANI, M. de. L. História da Educação Especial no Paraná: depoimento [maio de 2017]. Entrevistadora: Neide da Silveira Duarte de Matos. Curitiba, 2017. 3 gravações de vídeos. Entrevista concedida a pesquisa de Doutorado em Psicologia - PPI/UEM.

JANNUZZI, G. de. M. A educação do deficiente no Brasil: dos primórdios ao início do século XX. Campinas, SP: Autores Associados, 2004. (Coleção Educação Contemporânea).

JANNUZZI, G. de. M. A luta pela educação do deficiente mental no Brasil. São Paulo: Cortez, 1985.

KASSAR, M. C. M. Educação especial na perspectiva da educação inclusiva: desafios da implantação de uma política nacional. Educar em Revista. Curitiba, Brasil, n. 41, p. 6179, jul./set. 2011. Editora UFPR.

LEONTIEV, A. N. O desenvolvimento do psiquismo. Lisboa: Livros Horizonte, 1978.

MAZZOTTA, M. J. S. Educação especial no Brasil: histórias e políticas públicas. São Paulo: Cortez, 2001.

MÉSZARÓS, I. Para além do capital: rumo a uma teoria da transição. Tradução de Paulo César Castanheira e Sérgio Lessa. Campinas: Ed. da UNICAMP; Boitempo, 2002.

NETTO, J. P. Capitalismo monopolista e Serviço Social. 5. ed. São Paulo: Cortez, 2006.

PARANÁ (Estado). Secretaria de Educação. Superintendência de Desenvolvimento Educacional. Diretoria de Planejamento e Informações. Série histórica das matrículas na educação básica por etapa de ensino e DPA. Curitiba, 2016. Disponível em: <http://www.educa cao.pr.gov.br/arquivos/File/Censo/serie_historica2016.pdf.>. Acesso em: 23 set. 2017.

PARANÁ (Estado). Secretaria de Estado da Educação - Departamento de Educação Especial. Fundamentos teórico-metodológicos para a Educação Especial. Curitiba, PR, 1994.

PARANÁ (Estado). Secretaria do Estado da Educação. Diretrizes Curriculares da Educação Especial para a construção de currículos inclusivos. Curitiba, 2006. Disponível em:

<http://www.educadores.diaadia.pr.gov.br/arquivos/File/diretrizes/dce_edespecial.pdf.>. Acesso em: 20 jul. 2015.

SAVIANI, D. Entrevista com Dermeval Saviani. Revista Quadrimestral da Associação Brasileira de Psicologia Escolar e Educacional, SP, v. 19, n. 3, p. 613-620, set./dez. 
2015. Entrevista concedida a Neide da Silveira Duarte de Matos e organização de Sonia Mari Shima Barroco.

SAVIANI, D. História das ideias pedagógicas no Brasil. 2. ed. Campinas, SP: Autores Associados, 2008a. (Coleção memória da Educação).

SAVIANI, D. Pedagogia histórico-crítica: primeiras aproximações. 10. ed. Campinas: Autores Associados, 2008b.

UNESCO. Declaração de Salamanca e linha de ação sobre necessidades educativas especiais. Brasília: CORDE, 1994.

VYGOTSKI, L. S. Obras escogidas: fundamentos de defectología. Tradução de Julio Guilhermo Blanck. Madrid: Visor Dist., 1997. Tomo v.

\section{Notas}

${ }^{1}$ PPI/UEM, UNIOESTE - Cascavel - neide.matos@ unioeste.br

2 PPI/UEM - contato@ soniashima.com.br

${ }^{3}$ Em 2013 foi promulgada a Lei no 12.796 , alterando a Lei no 9.394, de 20 de dezembro de 1996, que estabelece as diretrizes e bases da educação nacional, para dispor sobre a formação dos profissionais da educação e dar outras providências, com a seguinte redação: "Art. 58. Entende-se por educação especial, para os efeitos desta Lei, a modalidade de educação escolar oferecida preferencialmente na rede regular de ensino, para educandos com deficiência, transtornos globais do desenvolvimento e altas habilidades ou superdotação".

${ }^{4}$ Vale dizer que o caráter caritativo da educação de pessoas com deficiência foi duramente criticado por L. S. Vygotski (1997), principal expoente da Psicologia Historico-Cultural, ao analisar a situação da Rússia e de outros países nas décadas de 1920 e 1930. Já nessas décadas este autor fizera a defesa de uma educação "forte" para tais pessoas, para instrumentalizá-las, de tal modo que pudessem compensar seus limites, enfrentando-os e superando-os. Vygotski é reconhecido pela teorização acerca da aprendizagem e do desenvolvimento de pessoas com e sem deficiências, bem como por sua atuação no âmbito da formação de professores, de elaboração de textos e de cartilhas, empregados em campanhas em prol da população alvo da chamada defectologia (área similar à Educação Especial).

${ }^{5}$ As campanhas eram soluções/alternativas para o financiamento imediato. Ex: Decreto $\mathrm{n}^{\mathrm{o}} 42.728$ criou a Campanha para Educação do Surdo Brasileiro (CESB) e Decreto 44.236 institui a Campanha Nacional de Educação e Reabilitação de Deficientes da Visão.

${ }^{6}$ Nota-se que, enquanto havia a demanda de preparar para o trabalho, havia também a necessidade de se trabalhar com a prevenção de deficiências. A ciência, sobretudo no campo da medicina, tinha muito a desvendar!

${ }^{7}$ Atendimento Educacional Especializado é um serviço da educação especial que organiza atividades, recursos pedagógicos e de acessibilidade, de forma complementar, suplementar à escolarização dos alunos com deficiência , transtornos globais do desenvolvimento e/ou altas habilidades/superdotação, matriculados nas classes comuns do ensino regular. (PARANÁ, 2016).

Submetido em: 13/11/2017

Aprovado em: 13/12/2017 